\title{
Extrasynaptic Glycine Receptors of Rodent Dorsal Raphe Serotonergic Neurons: A Sensitive Target for Ethanol
}

\author{
Edward P Maguire', Elizabeth A Mitchell',3, Scott J Greig', Nicole Corteen², David JK Balfour', \\ Jerome D Swinny ${ }^{2}$, Jeremy J Lambert ${ }^{1,4}$ and Delia Belelli*, \\ 'Division of Neuroscience, Medical Research Institute, Ninewells Hospital and Medical School, Dundee University, Dundee, UK; ${ }^{2}$ Institute for \\ Biomedical and Biomolecular Sciences, School of Pharmacy and Biomedical Sciences, University of Portsmouth, Portsmouth, UK
}

\begin{abstract}
Alcohol abuse is a significant medical and social problem. Several neurotransmitter systems are implicated in ethanol's actions, with certain receptors and ion channels emerging as putative targets. The dorsal raphe (DR) nucleus is associated with the behavioral actions of alcohol, but ethanol actions on these neurons are not well understood. Here, using immunohistochemistry and electrophysiology we characterize DR inhibitory transmission and its sensitivity to ethanol. DR neurons exhibit inhibitory 'phasic' post-synaptic currents mediated primarily by synaptic GABA $A_{A}$ receptors $\left(G A B A_{A} R\right.$ ) and, to a lesser extent, by synaptic glycine receptors (GlyR). In addition to such phasic transmission mediated by the vesicular release of neurotransmitter, the activity of certain neurons may be governed by a 'tonic' conductance resulting from ambient GABA activating extrasynaptic GABA $\mathrm{A}_{\mathrm{Rs}}$. However, for DR neurons extrasynaptic GABA $A_{A}$ s exert only a limited influence. By contrast, we report that unusually the GlyR antagonist strychnine reveals a large tonic conductance mediated by extrasynaptic GlyRs, which dominates DR inhibition. In agreement, for DR neurons strychnine increases their input resistance, induces membrane depolarization, and consequently augments their excitability. Importantly, this glycinergic conductance is greatly enhanced in a strychnine-sensitive fashion, by behaviorally relevant ethanol concentrations, by drugs used for the treatment of alcohol withdrawal, and by taurine, an ingredient of certain 'energy drinks' often imbibed with ethanol. These findings identify extrasynaptic GlyRs as critical regulators of DR excitability and a novel molecular target for ethanol.

Neuropsychopharmacology (2014) 39, I232-1244; doi:I0.1038/npp.2013.326; published online 8 January 20I4
\end{abstract}

Keywords: glycine; tonic inhibition; alcohol; serotonin dorsal raphe

\section{INTRODUCTION}

Alcoholism is a significant addictive disorder, associated with considerable medical, social, and economic costs (Nutt et al, 2010). The behavioral effects of ethanol include euphoria, loss of motor control, sedation, and anxiolysis (Harris et al, 2008; Mihalek et al, 2001). The mesolimbic dopaminergic system has been implicated in the rewarding properties of ethanol (Gonzales et al, 2004). However, animal and clinical studies identify an additional important role for serotonergic neurotransmission originating from the raphe nuclei (Lanteri et al, 2008; LeMarquand et al, 1994a, b; Lyness and Smith, 1992). Recombinant receptor studies reveal the function of certain $\mathrm{GABA}_{\mathrm{A}}$ receptors

* Correspondence: Dr D Belelli, Division of Neuroscience, Medical Research Institute, Ninewells Hospital and Medical School, Dundee University, Dundee DDI9SY, UK, Tel: +44I 382383 I50, Fax: +44I 382 383647, E-mail: d.belelli@dundee.ac.uk

${ }^{3}$ Current address: Oxford PharmaGenesis Ltd, Tubney Warren Barn, Tubney, Oxford OXI3 5QJ, UK.

${ }^{4}$ Senior Author.

Received 25 April 2013; revised 17 October 2013; accepted 12 November 2013; accepted article preview online 22 November 2013
$\left(\mathrm{GABA}_{\mathrm{A}} \mathrm{Rs}\right)$ and strychnine-sensitive glycine receptors (GlyRs) to be enhanced by behaviorally relevant concentrations $(10-100 \mathrm{mM})$ of ethanol, suggesting that these inhibitory receptors may be alcohol targets (Harris et al, 2008; Perkins et al, 2010). Although the dorsal raphe (DR) is implicated in rewarding and addictive behavior (Kranz et al, 2010), the influence of ethanol on glycinergic and GABAergic inhibition in the DR neurons has not been assessed. Here, we have utilized electrophysiology and immunohistochemistry to investigate the physiological and pharmacological properties of mouse serotonergic DR $\mathrm{GABA}_{\mathrm{A}} \mathrm{Rs}$ and GlyRs. We reveal that these neurons utilize a synergistic organization for inhibition whereby $\mathrm{GABA}_{\mathrm{A}} \mathrm{Rs}$ primarily mediate synaptic 'phasic' inhibition, but act in concert with extrasynaptic GlyRs, which provide a large 'tonic' inhibition that profoundly decreases neuronal excitability. Importantly, although a behaviorally relevant concentration $(30 \mathrm{mM})$ of ethanol had little effect upon $\mathrm{GABA}_{\mathrm{A}} \mathrm{R}$-mediated synaptic inhibition, it greatly and selectively enhanced the extrasynaptic glycinergic tonic and phasic conductance, thereby suppressing DR neuron firing. Furthermore, this GlyR-mediated conductance was greatly increased by clomethiazole, used clinically to treat 
alcohol withdrawal (Williams and McBride, 1998), sarcosine, which inhibits the GlyT1 transporter, an action reported to decrease ethanol intake and preference in rats (Molander et al, 2007), and by taurine, an ingredient of certain 'energy drinks' often consumed with ethanol.

Collectively, our findings reveal a crucial role for DR extrasynaptic GlyRs in influencing neuronal excitability. Our pharmacological studies suggest that an interaction with DR GlyRs may contribute to the behavioral actions of ethanol and the efficacy of certain treatments for alcoholism. These extrasynaptic receptors should allow a better understanding of how ethanol influences behavior and may represent a new target to treat alcohol abuse (Li et al, 2012; Yevenes and Zeilhofer, 2011).

\section{MATERIALS AND METHODS}

\section{Husbandry}

Mice were group-housed throughout and were given free access to food and water in a vivarium at $21 \pm 2{ }^{\circ} \mathrm{C}$ and $55 \%$ humidity. The holding room lights were on between 0600 and 1800 hours daily. The $\delta^{0 / 0}$ mice, together with wild-type (WT) control mice utilized for immunohistochemical analysis, were generated on a single C57BL6 background as described previously (Mihalek et al, 2001). All procedures involving experimental animals were performed in accordance with the Animals (Scientific Procedures) Act, 1986 (UK) and under the auspices of the Project Licence PIL 60/4005.

\section{Slice Preparation and Electrophysiology}

Dorsal raphe (DR) or nucleus accumbens (NAcc) slices were prepared from C57BL6 mice (P17-30) of either sex. Mice were killed by cervical dislocation. The brain was removed and placed in ice-cold artificial cerebrospinal fluid (aCSF) containing, in mM, $126 \mathrm{NaCl}, 26 \mathrm{NaHCO}_{3}, 10 \mathrm{MgSO}_{4}, 10$ Glucose, $2.5 \mathrm{KCl}, 1.25 \mathrm{NaH}_{2} \mathrm{PO}_{4}, 0.5 \mathrm{CaCl}_{2}, \mathrm{pH} 7.4$ when bubbled with $95 \% \mathrm{O}_{2}, 5 \% \mathrm{CO}_{2}$. Coronal sections $(300 \mu \mathrm{m})$ were cut using a Vibratome Series 1000 microtrome (Intracel) and incubated in oxygenated aCSF at room temperature for a minimum of $1 \mathrm{~h}$.

Whole-cell patch-clamp recordings were made from DR or medium spiny neurons (MSNs) of the NAcc core (Dixon et al, 2010) visually identified with an Axioskop 2 FS (Zeiss) microscope, equipped with IR-DIC optics. Patch electrodes were prepared from borosilicate glass (Garner Glass) with an open tip resistance of 3-5 M $\Omega$ when filled with intracellular solution (ICS) containing, in $\mathrm{mM}, 140 \mathrm{CsCl}$, 10 HEPES, 10 EGTA, $2 \mathrm{MgCl}_{2}, 1 \mathrm{CaCl}_{2}, 2 \mathrm{Mg}$-ATP, and 5 QX-314 ( $\mathrm{pH} 7.2-7.3,305-310 \mathrm{mOsm})$.

Using an Axopatch-1D amplifier (Molecular Devices) in the whole-cell configuration of the patch-clamp recording technique, miniature inhibitory post-synaptic currents (mIPSCs) and the holding current were recorded at a holding potential $\left(V_{H}\right)$ of $-60 \mathrm{mV}$ and $35^{\circ} \mathrm{C}$ in an extracellular solution (ECS) containing, in $\mathrm{mM}, 126 \mathrm{NaCl}$, $26 \mathrm{NaHCO}_{3}, 10$ glucose, $2.95 \mathrm{KCl}, 2 \mathrm{MgCl}_{2}, 2 \mathrm{CaCl}_{2}$, and 1.25 $\mathrm{NaH}_{2} \mathrm{PO}_{4}$ (306-309 mOsm) in the presence of $2 \mathrm{mM}$ kynurenic acid and $0.5 \mu \mathrm{M}$ tetrodotoxin (TTX). GABA $\mathrm{R}$ and GlyR mIPSCs were isolated using selective antagonists of the GlyR (strychnine hydrochloride) and the $\mathrm{GABA}_{\mathrm{A}} \mathrm{R}$ (bicuculline methobromide), respectively.

Cell-attached recordings were made at $30{ }^{\circ} \mathrm{C}$ in the absence of a glutamate receptor antagonist in ECS containing the $\alpha_{1}$ adrenergic receptor agonist phenylephrine to elicit regular neuronal firing (Judge et al, 2004). Patch electrodes were filled with ECS. Action currents were recorded with a voltage-clamp that maintained a 0-pA leak current (Perkins, 2006). Whole-cell current-clamp recordings were made at $30^{\circ} \mathrm{C}$ in ECS. Patch electrodes were filled with a potassium gluconate-based ICS, composed of (in $\mathrm{mM}) 130 \mathrm{~K}$ gluconate, $10 \mathrm{HEPES}, 10 \mathrm{EGTA}, 2 \mathrm{Mg}$-ATP, 1 $\mathrm{NaCl}, 1 \mathrm{MgCl}_{2}$, and $0.5 \mathrm{Na}-\mathrm{GTP}$ (Sigma), ( $\mathrm{pH} \mathrm{7.2,300-}$ $310 \mathrm{mOsm}$ adjusted with $\mathrm{D}$-mannitol). The liquid junction potential was corrected (Neher, 1992).

Data analysis. Recordings were acquired via digital audiotape using a Sony PCM-R300 and a DRA-200 interface (BioLogic) and analyzed offline with Strathclyde Electrophysiology Software, Electrophysiology Data Recorder/Whole cell Analysis Program (WinEDR/WinWCP; courtesy of Dr John Dempster, University of Strathclyde, UK). Details of the data analysis are supplied in the Supplementary Information.

Reagents and drugs. All reagents were obtained from Sigma-Aldrich-RBI, Tocris, or VWR unless otherwise stated. GABA, strychnine hydrochloride, sarcosine, clomethiazole (all from Sigma-Aldrich-UK), bicuculline methobromide (Tocris, Bristol, UK), and GES (Toronto Research Chemicals, Canada) were prepared as aqueous stock solutions and then diluted to the required concentration in ECS. Cyclothiazide (Tocris, Bristol, UK) was prepared as a 1000 -fold concentrated stock in DMSO and diluted to the desired concentration with ECS. The final DMSO concentration $(0.1 \%)$ had no effect upon the GlyR-mediated response. All drugs were applied to the brain slice via the perfusion system $(3-6 \mathrm{ml} / \mathrm{min})$ and allowed to infiltrate the slice for a minimum of $10 \mathrm{~min}$ before recordings were acquired. Because of the low frequency of GlyR mIPSCs, the effect of ethanol upon GlyR mIPSCs properties was evaluated by comparing GlyR mIPSCs recorded from slices pre-treated for $10 \mathrm{~min}$ with ethanol $(30 \mathrm{mM})$ with those recorded from slices incubated in ECS for the same duration.

Statistical analysis. All data are presented as the arithmetic mean \pm SEM. The statistical significance of measurements was calculated using the Student's $t$-test (paired or unpaired), regular ANOVA, or repeated measure ANOVA (for normalized data) using Microsoft Excel and SigmaStat as appropriate. The non-parametric Kolmogorov -Smirnoff (KS) test (SPSS v15) was used to compare the inter-event interval (IEI) in control recordings and after drug application and, with the exception of the effect of ethanol upon GlyR mIPSCs (see above), to compare populations of individual events (mIPSCs) before and after drug application to a given cell using a stringent criterion for significance $(P<0.01)$.

\section{Immunohistochemistry}

Tissue preparation for immunohistochemistry. The data presented in this study is derived from two WT and 

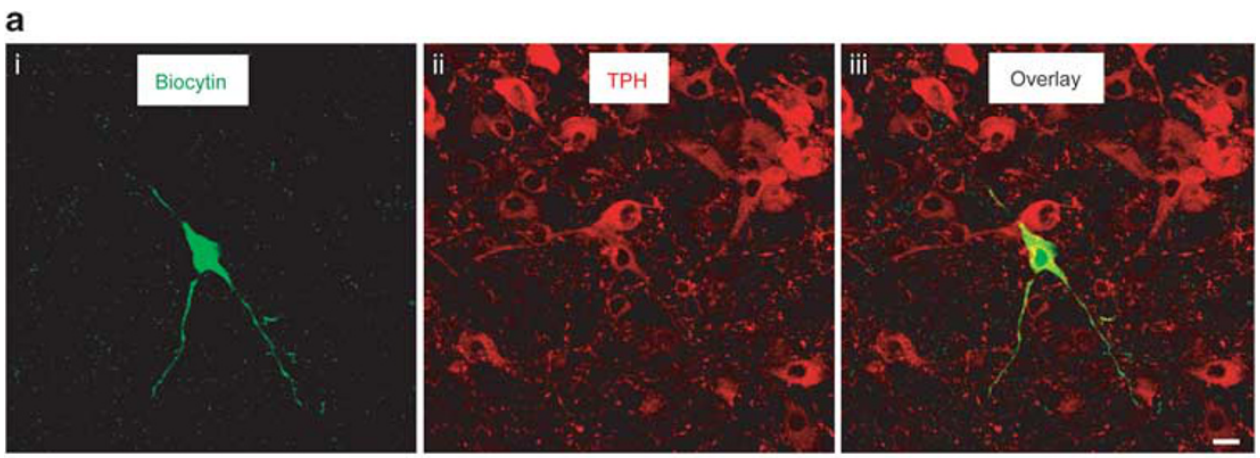

b

C
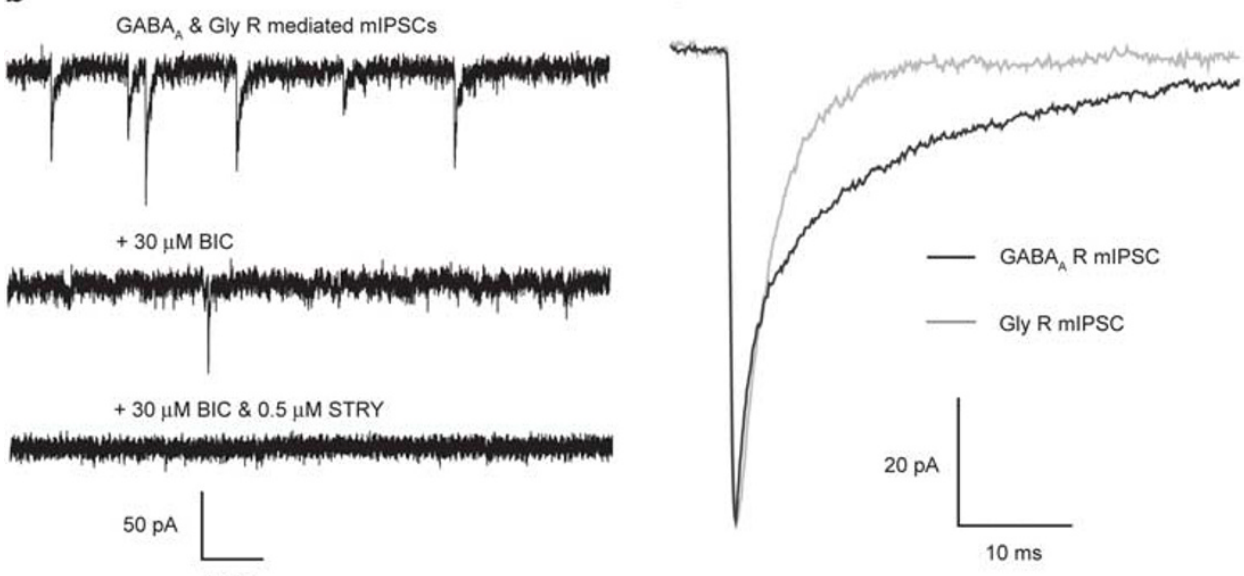

Figure I The majority of mIPSCs recorded from serotonergic DR neurons are mediated by synaptic GABA $\mathrm{Rs}_{\mathrm{A}}$. (a) A representative image of one of the recorded and filled DR neurons indicating that it is a serotonergic neuron. (i) Shows biocytin labelling within the recorded cell, (ii) illustrates immunoreactivity for tryptophan hydroxylase (TPH), a marker for serotonergic neurons, and (iii) the overlay confirms that the recorded cell expresses TPH. Bar $=10 \mu \mathrm{m}$. (b) Illustrated are sections ( $2 \mathrm{~s}$ duration) of whole-cell voltage-clamp recordings of mIPSCs obtained from a representative DR neuron in the presence of $2 \mathrm{mM}$ kynurenic acid and $0.5 \mu \mathrm{M}$ TTX before (top trace) and after the bath application of the $\mathrm{GABA}_{\mathrm{A}} \mathrm{R}$ antagonist bicuculline (BIC, $30 \mu \mathrm{M}$ - middle trace) or the combined application of bicuculline $(30 \mu \mathrm{M})$ and the glycine receptor antagonist strychnine (STRY, $0.5 \mu \mathrm{M}$-bottom trace). The majority of mIPSCs are blocked by bicuculline, indicating that they are mediated by GABA $\mathrm{A}_{\mathrm{A}}$. The remaining mIPSCs are mediated by GlyRs as demonstrated by their blockade following the application of strychnine. Note the higher frequency and slower decay of the GABA $A_{A}$ Rs compared with GlyRs mIPSCs. (c) Normalized (to peak amplitude) ensemble averages of exemplar GABA $A_{A} R$ (black) and GlyR (grey) mIPSCs superimposed on the same scale to illustrate the differences in their decay kinetics. Note the GlyR-mediated mIPSCs exhibit a faster decay, which is approximately half that of the GABA $A_{A}$-mediated mIPSCs.

two $\delta^{0 / 0}$ adult male mice. Anesthesia was induced with isoflurane and maintained with urethane $(1.25 \mathrm{~g} / \mathrm{kg}$ of bodyweight; i.p.). The animals were perfused transcardially with $0.9 \%$ saline solution for $3 \mathrm{~min}$, followed by a 15 -min fixation with $1 \%$ paraformaldehyde and $15 \% \mathrm{v} / \mathrm{v}$ saturated picric acid in $0.1 \mathrm{M}$ phosphate buffer (PB), $\mathrm{pH}$ 7.4. The brains were kept in the same fixative solution overnight at $4{ }^{\circ} \mathrm{C}$. Coronal sections of the DR and NAcc, $50-\mu \mathrm{m}$ thick, were prepared on a Vibratome and stored in $0.1 \mathrm{M} \mathrm{PB}$ containing $0.05 \%$ sodium azide.

Immunohistochemical reactions. Visualization of biocytinfilled cells. To confirm that the recorded cells were serotonergic, biocytin was added to the intracellular electrolyte of the patch electrode. Immunohistochemistry for tryptophan hydroxylase (TPH) - to identify the DR - and visualization of biocytin (to identify the labelled cell) was performed according to our previous protocols (Swinny et al, 2010).

Visualization of GlyR expression. The immunohistochemical protocols are as described previously (Corteen et al, 2011). The following antibodies were used: (1) a mouse monoclonal antibody mAb4a against the GlyR, (1:2000; Pfeiffer et al, 1984; a gift from Heinrich Betz, Max-Planck Institute for Brain Research, Frankfurt, Germany); (2) a polyclonal antibody against neuroligin2 (NL2) used to visualize inhibitory synapses, (1:1000; Briatore et al, 2010; Synaptic Systems, catalogue number 129203); (3) a polyclonal antibody against TPH used to visualize serotonergic neurons, (1:3000) (Millipore, catalogue number AB1541); (4) a polyclonal antibody against dopamine (DA) and adenosine $3^{\prime}, 5^{\prime}$-monophosphate-regulated phosphoprotein of $32 \mathrm{kDa}$ (DARPP-32) used to visualize MSNs of the NAcc (1:250; Santa Cruz, catalogue number sc-8483); and (5) a polyclonal antibody against the $\delta$ subunit of the $\mathrm{GABA}_{\mathrm{A}} \mathrm{R}$ (a gift from Werner Sieghart). Sections were examined with a confocal laser-scanning microscope (LSM710; Zeiss) using a Plan Apochromatic $100 \times$ DIC oil objective (NA1.46). All images presented represent a single optical section.

Quantification of the density of NL2 and GlyR clusters and their relative proportion of co-localization on TPH or DARPP-32-immunopositive profiles. Tissue from two 
a
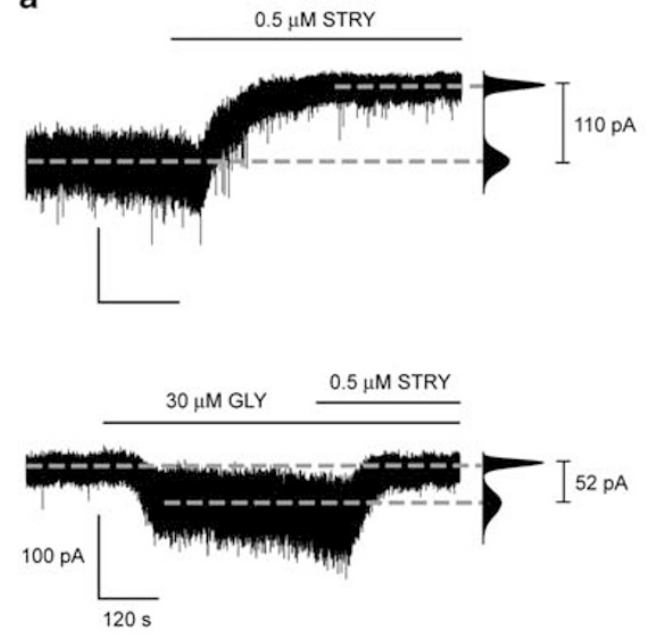

b

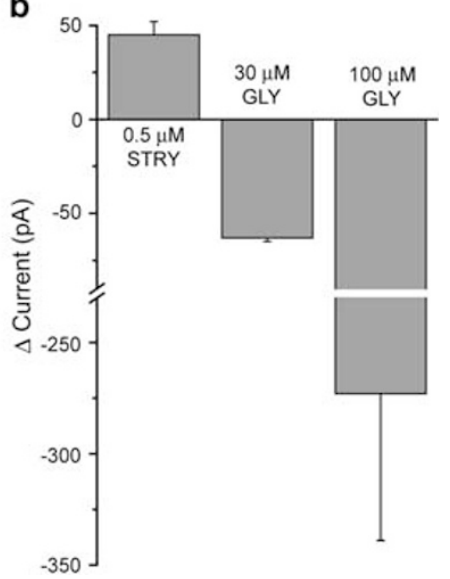

Figure 2 DR neurons exhibit a large tonic inhibitory conductance mediated by extrasynaptic GlyRs. (a) Representative recordings $\left(V_{H}=-60 \mathrm{mV}\right)$ from DR neurons (left), illustrating the outward and inward current induced by $0.5 \mu \mathrm{M}$ strychnine (STRY, top trace) and $30 \mu \mathrm{M}$ glycine (GLY, bottom trace), respectively. The corresponding all-points histograms are given to the right of the traces. Note that the exemplar 5-HT neuron illustrated in the top trace exhibits a large tonic conductance as revealed by strychnine, whereas although the neuron illustrated in the bottom trace exhibits an inward current when challenged with $30 \mu \mathrm{M}$ glycine, the subsequent application of strychnine only returns the holding current to the pre-glycine level, ie, in the absence of added glycine, this particular neuron does not exhibit an endogenous tonic conductance. (b) A graph summarizing the changes in holding current evoked by strychnine $(0.5 \mu \mathrm{M}, n=3 \mathrm{I})$ and glycine $(30$ and $100 \mu \mathrm{M}, n=44$ and I0, respectively) for the responsive neurons, ie, 62, 90, and I00\% for strychnine, glycine $30 \mu \mathrm{M}$, and glycine $100 \mu \mathrm{M}$ challenges, respectively. Error bars indicate SEM. Labels are the same for calibration bars shown in top and bottom traces.

animals (four DR sections and four NAcc sections, two sections per region per animal) was used to quantify the density (number of clusters per $1000 \mu \mathrm{m}^{2}$ ) of NL2 and GlyR clusters and the proportion of GlyR clusters, which colocalize with NL2, according to previously published methods (Corteen et al, 2011). Three fields of view (FOV) were randomly selected within the midline of the DR or the core of the NAcc of each tissue section and Z-stacks consisting of three optical sections were acquired for each FOV ( $n=9$ optical sections per section of tissue). Within a FOV, the number of puncta within an optical section and the number of puncta that co-localized was manually counted using the Image J software. The means \pm SD for all fields of view within, between sections, and between animals were compared for statistical differences using the KruskalWallis one-way analysis of variance. These values were then pooled as there were no statistical differences $(P>0.05)$ between the different FOV, between sections, and between animals. The mean $\pm S D$ density data presented are thus derived from a total of 36 optical sections for the DR and 36 for the NAcc.

\section{RESULTS}

\section{Phasic and Tonic Inhibitory Transmission in Serotonergic Dorsal Raphe Neurons}

All recordings were made from DR neurons situated medially throughout the rostral caudal axis. In the mouse, the large majority of these neurons are serotonergic, with GABAergic neurons restricted to the lateral wings (Brown et al, 2008; Calizo et al, 2011). Confirmation that the recorded cells were serotonergic was obtained by post-hoc immunohistochemical analysis of biocytin-filled cells (Figure 1a) and by currentclamp recordings, revealing the focal application of $5-\mathrm{HT}$
$(100 \mu \mathrm{M})$ to produce a membrane hyperpolarization of such neurons (data not shown). To characterize neuronal phasic inhibition that is mediated by the transient activation of synaptic receptors, DR neurons were voltage-clamped $(-60 \mathrm{mV})$ to record mIPSCs (Figure $1 \mathrm{~b})$. The frequency of such events was greatly reduced by bicuculline $(30 \mu \mathrm{M})$, confirming that they are primarily mediated by synaptic $\mathrm{GABA}_{\mathrm{A}}$ Rs. However, in the presence of bicuculline and the ionotropic glutamate receptor antagonist kynurenic acid, mIPSCs were still evident, albeit at a low frequency. Such events were abolished by strychnine $(0.5 \mu \mathrm{M})$, demonstrating that they are mediated by synaptic GlyRs (Figure 1b). Although both $\mathrm{GABA}_{\mathrm{A}} \mathrm{R}$ - and GlyR-mediated mIPSCs were evident for all DR neurons, their properties were distinct. In particular, the decay times of glycine-mediated mIPSCs were $50 \%$ less than those mediated by GABA and, in agreement with the limited glycinergic innervation of the DR (Rampon et al, 1999), their frequency of occurrence was considerably lower (Figure 1c, Supplementary Table S1A). Note that gender did not influence the properties of either $\mathrm{GABA}_{\mathrm{A}} \mathrm{R}$ or GlyR-mediated mIPSCs, and data were therefore pooled (Supplementary Table S1A).

To investigate whether DR neurons exhibit a tonic inhibitory conductance that is mediated by ambient transmitter activating either $\mathrm{GABA}_{\mathrm{A}} \mathrm{Rs}$ and/or GlyRs (Farrant and Nusser, 2005), the effect on the holding current $\left(V_{H}=-60 \mathrm{mV}\right)$ of bicuculline $(30 \mu \mathrm{M})$ or strychnine $(0.5 \mu \mathrm{M})$, respectively, was determined. The $\mathrm{GABA}_{\mathrm{A}} \mathrm{R}$ antagonist induced an outward current $(26 \pm 8 \mathrm{pA} ; n=5)$ in only $28 \%$ of neurons ( $n=5$ of 18 tested). Bicucullineinsensitive neurons may nevertheless express extrasynaptic $\mathrm{GABA}_{\mathrm{A}} \mathrm{Rs}$ that are inactive, due to low ambient GABA. However, the bath application of $10 \mu \mathrm{M}$ GABA, a concentration greater than that usually used to activate extrasynaptic $\mathrm{GABA}_{\mathrm{A}} \mathrm{Rs}$ (Scimemi et al, 2005; Wlodarczyk et al, 

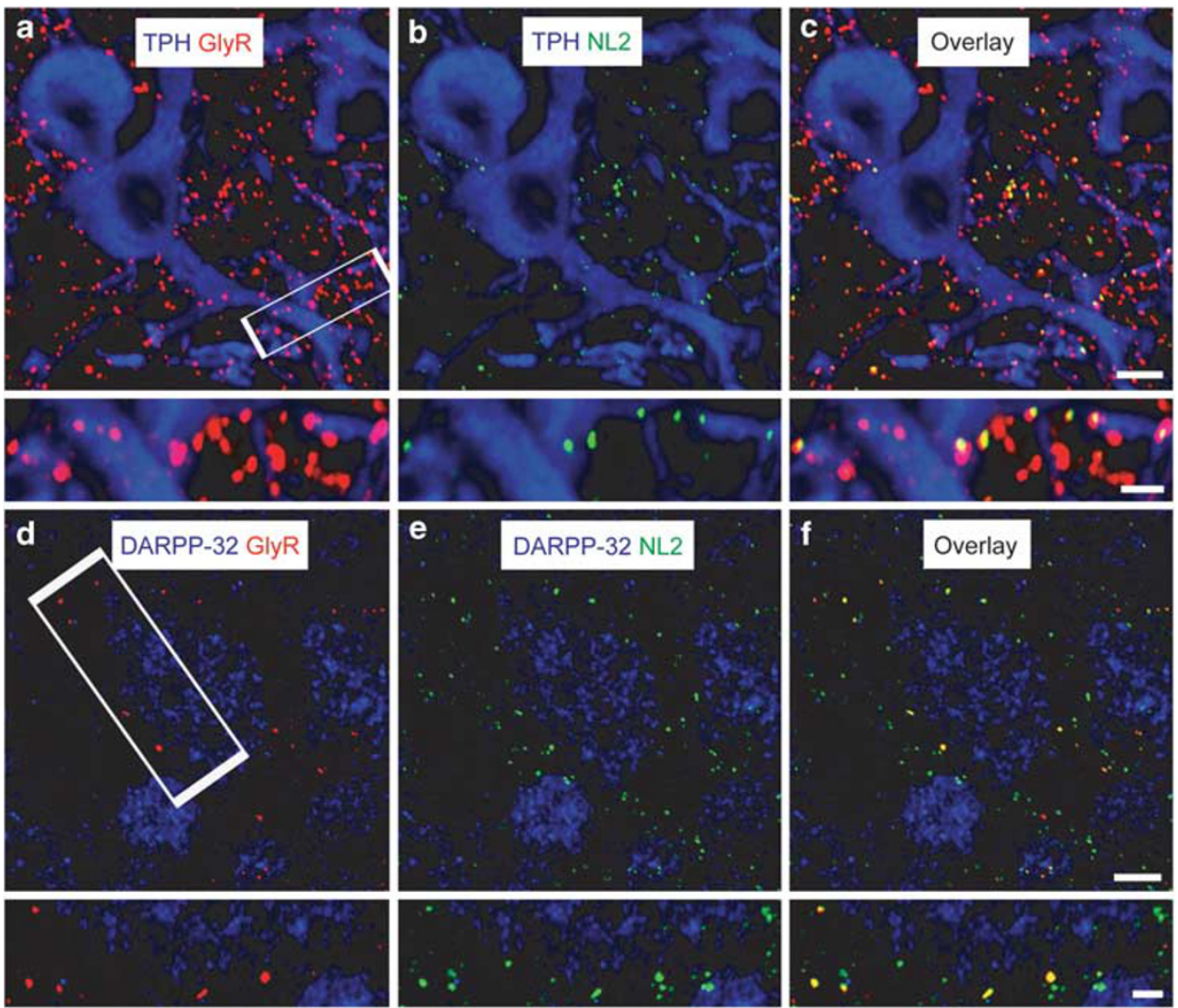

Figure 3 Distribution of GlyR expression and inhibitory synapses in the DR and NAcc. (a) An intense punctate GlyR staining (red) is evident on the membranes of serotonergic cells stained with TPH (blue) in the DR. (b) The inhibitory synaptic marker protein, neuroligin2 (NL2; green) shows punctate staining mainly on the dendrites of TPH-immunopositive cells (blue). (c) An overlay of a and b reveals that some GlyR puncta co-localize with NL2 puncta (yellow). Note that a significant proportion of GlyR puncta, particularly on the TPH dendrites, do not co-localize with NL2, suggesting an extrasynaptic locus of expression. (d) In contrast to the DR, putative medium spiny neurons of the NAcc stained for DARPP-32 (blue) show much fewer GlyR-immunopositive puncta (red). (e) NL2 puncta (green) in the NAcc are located on somata and dendritic compartments. (f) In contrast to the DR, the majority of the GlyR puncta co-localize with NL2 in the NAcc (yellow). For each pair of images, the bottom image is a magnified section (defined by the white rectangle) of the corresponding top image. Bars $=5 \mu \mathrm{m}$ (top images) and $2 \mu \mathrm{m}$ (bottom images).

2013), did not induce a change in the holding current, or membrane current noise (RMS) (Supplementary Figure S1a), suggesting that only a limited neuronal population express extrasynaptic $\mathrm{GABA}_{\mathrm{A}} \mathrm{Rs}$. Moreover, after the application of GABA, the bath application of bicuculline $(30 \mu \mathrm{M})$ revealed a small tonic current in only $\sim 30 \%$ of the neurons tested (data not shown). By contrast, in the absence of exogenous glycine, $62 \%$ of neurons were sensitive to strychnine (31 of 50 tested), producing an outward current for responsive neurons $(45 \pm 7 \mathrm{pA} ; n=31)$, considerably greater than that produced by bicuculline (Figure 2a, top trace and $b$ ). Furthermore, the bath application of glycine induced an inward current in $90 \%(30 \mu \mathrm{M} ;-64 \pm 8 \mathrm{pA}, 44$ of the 49 tested) and $100 \%(100 \mu \mathrm{M} ;-273 \pm 66 \mathrm{pA}, n=10)$ of neurons tested (Figure 2a, bottom trace and b). Gender did not influence the glycinergic tonic conductance, the amplitude of the glycine-evoked current, or the percentage of sensitive neurons, and thus data were pooled (Supplementary Table S1B). Similarly, the focal pressure application of glycine ( $15 \mathrm{psi}, 10-30 \mathrm{~ms}$ duration, $300 \mu \mathrm{M}$ ) induced an inward current for all neurons tested $(-120 \pm 19 \mathrm{pA}$, $n=5$ ). Collectively, these findings reveal all serotonergic DR neurons to express GlyRs and, for the majority of neurons, these receptors mediate a large resident tonic current.
Confocal immunohistochemistry was used to further investigate the expression of GlyRs in the DR and to elucidate the proportion of receptors expressed within synapses as indicated by the inhibitory synaptic marker, NL2 (Varoqueaux et al, 2004). Labelling of GlyRs with the well-characterized mouse monoclonal pan antibody mAb4a (Pfeiffer et al, 1984) revealed numerous, membrane-bound immunoreactive clusters on somatic and dendritic compartments of TPH-immunopositive cells (Figure 3a, b and c), with the glycinergic clusters being similar to those described for other brain regions eg brain stem (Lorenzo et al, 2007). However, the majority of GlyR-immunopositive puncta did not co-localize with NL2 puncta (Figure 3a-c). Thus, quantitative analysis of GlyR- and NL2-immunopositive clusters revealed a mean cluster density of $75 \pm 14$ and $54 \pm 12$ (clusters $/ 1000 \mu \mathrm{m}^{2}$ ), respectively, although only $\sim 41 \%\left(31 \pm 11 / 1000 \mu^{2}\right)$ of GlyR clusters co-localized with NL2 clusters. This finding contrasts with the comparative labelling density of GlyR clusters determined on MSNs of the NAcc (Figure 3d-f), made under identical conditions in the same animals. The quantified density of GlyR clusters in the NAcc was $25 \pm 8 / 1000 \mu \mathrm{m}^{2}$, which equates to only $33 \%$ of the GlyR cluster density measured in the DR. However, $61 \%\left(14 \pm 6 / 1000 \mu \mathrm{m}^{2}\right)$ of GlyR puncta in these neurons co-localized with NL2, suggesting that the 
a

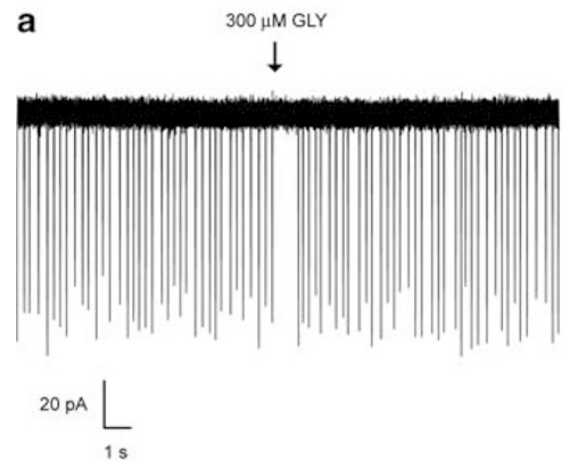

C

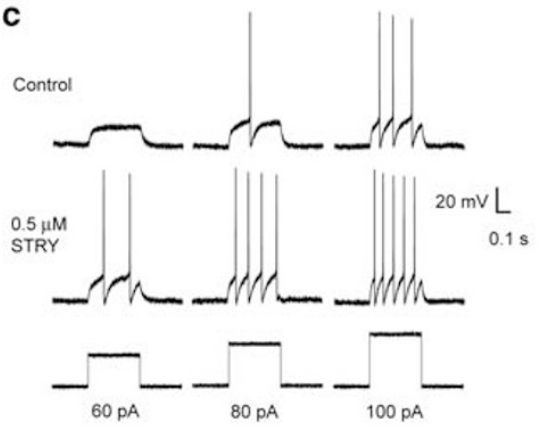

b

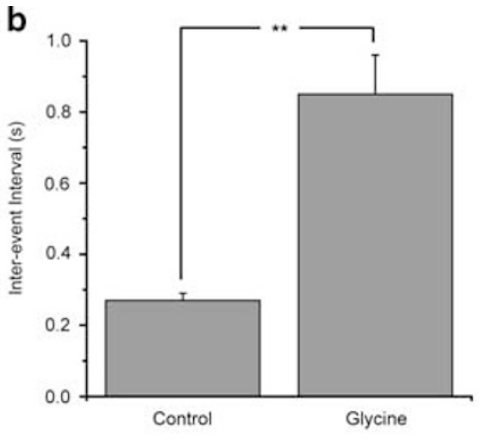

d

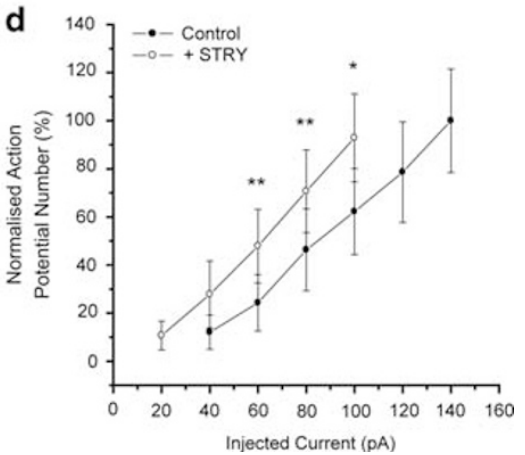

Figure 4 In DR neurons, extrasynaptic GlyRs greatly influence neuronal excitability. (a) A representative cell-attached voltage-clamp recording of action currents illustrating the suppression of their discharge (in the presence of phenylephrine $10 \mu \mathrm{M}$ ) by the focal application (duration $20 \mathrm{~ms}$, pressure 15 psi) of $300 \mu \mathrm{M}$ glycine (GLY) to an individual DR neuron. (b) A bar chart illustrating the mean increase (for the seven neurons tested) of the inter-event interval produced by the focal application of $300 \mu \mathrm{M}$ glycine. (c) Representative whole-cell current-clamp recording of action potentials elicited in response to a subset of current pulses (bottom traces; 60-100 pA) in control conditions (top traces) and following the bath application of $0.5 \mu \mathrm{M}$ strychnine (STRY lower traces). Note the increase in action potential (AP) frequency following strychnine application in these exemplar traces. (d) A graph depicting the input-output relationship for the seven DR neurons in control conditions $(\mathbf{O})$ and in the presence of strychnine $(O)$. The response is expressed normalized to the averaged maximum number of APs elicited in response to current injection steps. Note that the input-output relationship is shifted to the left in the presence of strychnine, thus indicating an increased neuronal excitability. $* P<0.05$; $* * P<0.0$ I, vs control by paired Student's t-test. Error bars indicate SEM.

level of expression, as well as the trafficking of GlyRs between synaptic and extrasynaptic compartments, is cell type specific (see below).

The influence of the resident glycinergic tonic conductance on DR neuronal excitability was investigated by utilizing strychnine. In both current- and voltage-clamp recordings, this GlyR antagonist $(1 \mu \mathrm{M})$ increased the input resistance in eight of the nine neurons tested (Supplementary Table S2). In these nine neurons, strychnine depolarized seven cells by an average of $6 \pm 1 \mathrm{mV}$ (Supplementary Table S2), with no change in the remaining two cells. To further assess the impact of GlyR activation upon the excitability of DR neurons, cell-attached voltage-clamp recordings of action currents were made (Perkins, 2006). To mimic the physiological noradrenergic input to the DR and produce regular neuronal firing, recordings were made in the presence of the $\alpha 1$-adrenoceptor agonist phenylephrine (Judge et al, 2004). Focally applied glycine $(300 \mu \mathrm{M})$ induced a transient, cessation of DR neuronal firing, which was sensitive to block by strychnine, in all cells tested (control IEI $=0.27 \pm 0.02 \mathrm{~s} ;$ glycine IEI $=0.85 \pm 0.11 \mathrm{~s}$, $P<0.01, n=7-$ Figure $4 \mathrm{a}$ and $\mathrm{b})$. Additionally, in currentclamp recordings in seven of the nine cells tested strychnine $(1 \mu \mathrm{M})$ produced a leftward shift of the input-output relationship and reduced the minimum current required to elicit action potential firing, ie, the rheobase, thus increasing the cell excitability (rheobase, control $=71 \pm 16$
$\mathrm{pA} ;+$ strychnine $=48 \pm 14 \mathrm{pA}, n=7, P<0.05$; see Materials and Methods and Figure $4 \mathrm{c}$ and $\mathrm{d}$ ).

\section{Dorsal Raphe GlyRs: a Relevant Ethanol Target?}

Independently, both the DR and GlyRs have been implicated in the actions of ethanol (Aguayo and Pancetti, 1994; Eggers and Bergers, 2004; LeMarquand et al, 1994a, b; Mascia et al, 1996; Perkins et al, 2010; Pistis et al, 1997; Valenzuela et al, 1998). Supporting a contribution of DR GlyRs to the behavioral actions of alcohol, the bath application of a concentration of ethanol $(30 \mathrm{mM})$, which results in mild intoxication, induced an inward current $(\Delta I=-43 \pm 18 \mathrm{pA} ; n=6$; Figure $5 \mathrm{a}$ and $\mathrm{c})$, which was blocked by the subsequent application of strychnine, and an associated increase in membrane current noise $(\Delta \mathrm{RMS}=4.2 \pm 1.1 \mathrm{pA} ; n=6)$ in 6 of the $9(67 \%)$ neurons tested (ie, a similar proportion of neurons to those sensitive to strychnine). Furthermore, in the presence of pre-applied glycine $(30 \mu \mathrm{M})$, ethanol $(30 \mathrm{mM})$ induced an additional strychnine-sensitive inward current in all neurons tested $(\Delta I=-77 \pm 12 \mathrm{pA} ; n=7 ;$ ie, an $\sim 2$-fold increase, $P<0.05$ $v s$ glycine alone-Figures $5 \mathrm{~b}, \mathrm{c}$ and $6 \mathrm{~b})$. Confirming ethanol specificity, a mannitol-based $(30 \mathrm{mM})$ hyper-osmotic ECS had no effect on the neuronal holding current or RMS $(P>0.05)$. This facilitatory effect of ethanol was additionally investigated by the brief, focal application of glycine 

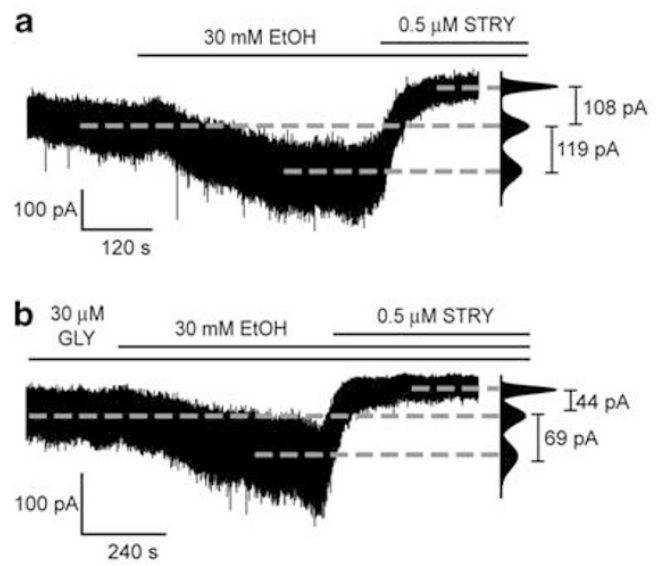

C

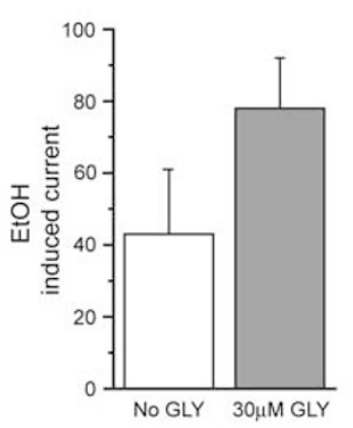

d

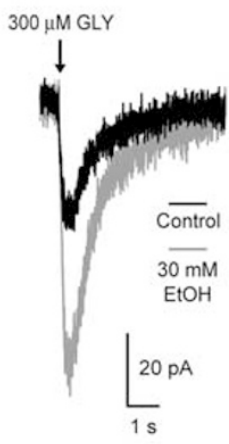

e

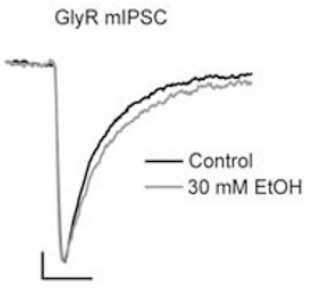

GABA $_{A} R$ mIPSC

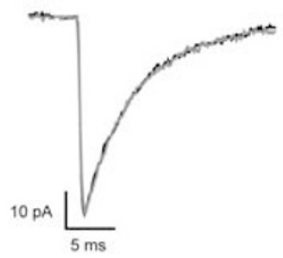

f

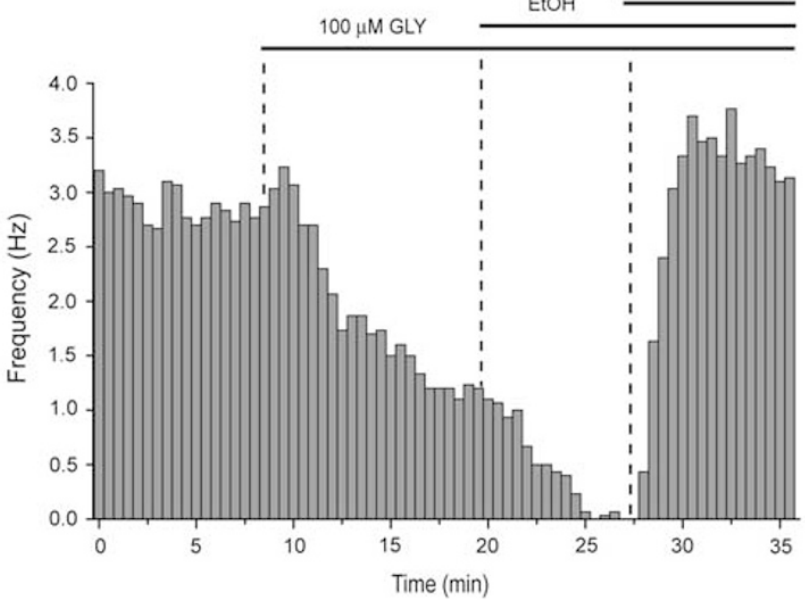

Figure 5 Ethanol enhances the function of DR GlyRs and suppresses neuronal excitability. (a) A representative whole-cell voltage-clamp recording illustrating that ethanol $(30 \mathrm{mM})$ - in the absence of added glycine - produces a large inward current, which is reversed by the subsequent application of strychnine (STRY, $0.5 \mu \mathrm{M}$ ) to beyond baseline (see corresponding all-points histogram on the right of the trace). Thus, ethanol acts to enhance the endogenous glycinergic tonic conductance. (b) A representative whole-cell voltage-clamp recording illustrating that ethanol (30 mM) -in the presence of $30 \mu \mathrm{M}$ glycine (GLY) — produces a large inward current, which is reversed by strychnine (STRY, $0.5 \mu \mathrm{M}$ ) to beyond baseline (see corresponding all-points histogram on the right). Thus, both the effects of glycine and ethanol are mediated by GlyRs. (c) A bar graph summarizing the current induced by the bath application of $30 \mathrm{mM}$ ethanol in the absence (white) or in the presence of $30 \mu \mathrm{M}$ glycine (grey) in six and seven DR neurons, respectively. Data are derived from ethanol-sensitive neurons only (six out of nine and seven out of seven in the absence and in the presence of $30 \mu \mathrm{M}$ glycine, respectively). Note that in the absence of added glycine, the proportion of ethanol-sensitive neurons (67\%) was similar to those sensitive to strychnine, ie, exhibiting an endogenous glycinergic conductance. (d) A representative whole-cell voltage-clamp recording of the current induced by the focal application (duration 20 ms, pressure $10 \mathrm{psi}$ ) of $300 \mu \mathrm{M}$ glycine to a DR neuron before and after the bath application of $30 \mathrm{mM}$ ethanol (EtOH). Note that ethanol increases the total charge transfer. (e) Representative normalized (to control peak amplitude) ensemble averages of GlyR- (top traces) and GABA $A_{A}$-mediated (bottom traces) mIPSCs in control conditions (black) and in the presence of $30 \mathrm{mM}$ ethanol (grey). Note that ethanol prolongs the decay of GlyR-mediated, but not that of GABA $A$-mediated, mIPSCs. Labels are the same for calibration bars shown for top and bottom traces. ( $f$ ) A frequency plot depicting the inhibition of action current discharge by $100 \mu \mathrm{M}$ glycine (in the presence of $10 \mu \mathrm{M}$ phenylephrine) obtained from a representative recording of a DR neuron. The plot further demonstrates that ethanol $(30 \mathrm{mM})$ enhances this inhibitory effect of glycine. Note that the subsequent application of strychnine not only reverses the inhibitory effects of glycine and ethanol but also increases the frequency of action current discharge to a level greater than control, thus suggesting the presence of a GlyR-mediated inhibitory tone.

$(300 \mu \mathrm{M})$. For all neurons tested, bath-applied ethanol $(30 \mathrm{mM})$ clearly enhanced the glycine-evoked current, and this effect was quantified as the total charge transfer, ie, area under the curve (control $=85 \pm 16 \mathrm{fC}$; ethanol $=166 \pm 37 \mathrm{fC}$; $n=5, P<0.05$ ) of such glycine-evoked currents (Figure $5 \mathrm{~d}$ ).

We next investigated whether DR synaptic GlyRs are ethanol sensitive. Ethanol $(30 \mathrm{mM})$ had no effect on the frequency, or amplitude of GlyR-mediated mIPSCs, but caused a clear prolongation of their decay time (Figure 5e, Table 1). Hence, both synaptic and extrasynaptic GlyRs of DR neurons are highly sensitive to ethanol. By contrast, ethanol $(30 \mathrm{mM})$ had no effect upon $\mathrm{GABA}_{\mathrm{A}} \mathrm{R}$-mediated mIPSC kinetics or amplitude, although it produced a modest but significant increase in their frequency in four of the six neurons tested $(P<0.01$ KS test; $134 \pm 3 \%$ of control; $n=4, P<0.01-$ Figure 5e, Table 1). Moreover, in the presence of GABA $(10 \mu \mathrm{M})$, ethanol $(30 \mathrm{mM}) \mathrm{did}$ not affect the holding current or the associated RMS (Supplementary Figure S1b). Extrasynaptic $\mathrm{GABA}_{\mathrm{A}}$ Rs containing the $\delta$ subunit ( $\delta$-GABA $\mathrm{As}$ ) are proposed targets of ethanol (Korpi et al, 2007; Mody et al, 2007). However, no $\delta$ protein immunoreactivity was detected in DR neurons 

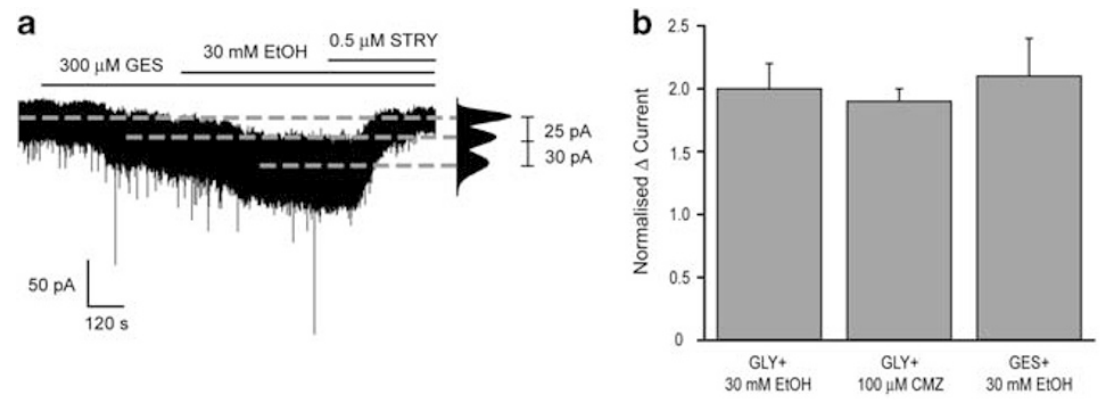

C
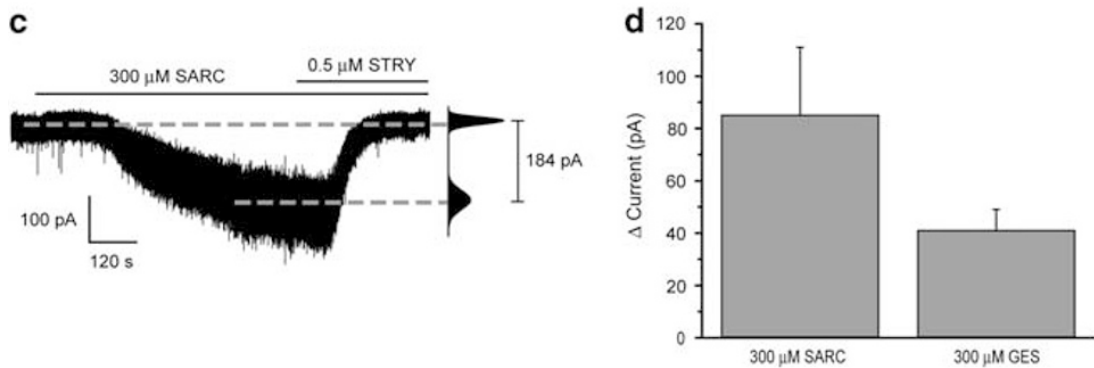

Figure 6 The GlyR-mediated tonic current of DR neurons is enhanced by inhibition of the Gly $T$ I or the taurine transporter, by clomethiazole (CMZ) and by ethanol. (a) A representative whole-cell voltage-clamp recording from a DR neuron illustrating the ethanol (EtOH, $30 \mathrm{mM}$ )-mediated increase of the GES $(300 \mu \mathrm{M})$-evoked current. Note that both effects are sensitive to block by strychnine (0.5 $\mu$ M STRY). The corresponding all-points histogram is given on the right of the trace. (b) A summary graph illustrating the fold increase for the responsive neurons of the (I) glycine ( $30 \mu \mathrm{M})$-evoked current by: ethanol $(30 \mathrm{mM}, n=7$; left column) and clomethiazole $(100 \mu \mathrm{M}, n=7$; centre column) and (2) the GES (300 $\mu \mathrm{M})$-evoked current by ethanol ( $30 \mathrm{mM}, n=5$; right column). Error bars indicate the SEM. (c) A representative whole-cell voltage-clamp recording from a DR neuron illustrating the GlyR-mediated inward current produced by the bath application of the GlyTI inhibitor sarcosine (SARC, $300 \mu \mathrm{M}$ ). Note that the current induced by sarcosine is sensitive to block by strychnine (STRY, $0.5 \mu \mathrm{M})$. (d) A bar graph summarizing the current induced in DR neurons by sarcosine $(300 \mu M, n=1 \mathrm{I})$ and the taurine transporter blocker, GES (300 $\mu \mathrm{M}, n=5)$. Error bars denote SEM.

Table I A Comparison of the Effect of $30 \mathrm{mM}$ Ethanol (EtOH), Upon the Properties of GlyR- and GABA $\mathrm{R}_{\mathrm{A}}$-Mediated mIPSCs

\begin{tabular}{|c|c|c|c|c|}
\hline & $\begin{array}{c}\text { Control GlyR } \\
\text { mIPSCs }(n=14)\end{array}$ & $\begin{array}{c}+30 \mathrm{mM} \text { EtOH } \\
\text { GlyR mIPSCs }(n=5)\end{array}$ & $\begin{array}{l}\text { Control GABA } R \\
\text { mIPSCs }(n=6)\end{array}$ & 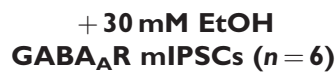 \\
\hline Peak amplitude (pA) & $-69 \pm 4$ & $-69 \pm 4$ & $-66 \pm 6$ & $-65 \pm 2$ \\
\hline$\tau(\mathrm{ms})$ & $3.8 \pm 0.2$ & $5.8 \pm 0.3 * * * *$ & $5.5 \pm 0.3$ & $6.2 \pm 0.4$ \\
\hline Frequency $(\mathrm{Hz})$ & $0.4 \pm 0.1$ & $0.8 \pm 0.6$ & $1.5 \pm 0.3^{+\ddagger}$ & $2.0 \pm 0.4^{+\ddagger}$ \\
\hline
\end{tabular}

${ }^{*} P<0.05$, **** $P<0.00 \mathrm{I}$, unpaired Student's $t$-test, comparing control and $+30 \mathrm{mM}$ ethanol for GlyR mIPSCs; ${ }^{\ddagger} P<0.0$ I, paired Student's $t$ test for GABA $\mathrm{R}$ mIPSCs; $+n=4$.

compared with the dentate gyrus and thalamic relay nuclei (Supplementary Figure S1c).

To further assess the impact of ethanol upon the excitability of DR neurons, cell-attached voltage-clamp recordings of action currents were performed in the presence of phenylephrine $(10 \mu \mathrm{M}$; Judge et al, 2004) and bicuculline $(30 \mu \mathrm{M})$. In the absence of added glycine, ethanol $(30 \mathrm{mM})$ reduced the frequency of action currents in one out of the seven cells tested (control: $3.4 \mathrm{~Hz} ;+$ ethanol: $2.5 \mathrm{~Hz} ; P<0.01$ by KS test; ie, a $25 \%$ reduction), while having no significant effect in the remaining neurons, possibly because glycine levels in the slices are insufficient for ethanol's action to affect phenylephrine-evoked firing. In agreement, bath-applied glycine $(100 \mu \mathrm{M})$ reduced the frequency of action currents from $2.6 \pm 0.2 \mathrm{~Hz}$ to $1.2 \pm 0.4 \mathrm{~Hz}$ (ie, a $54 \%$ reduction; $P<0.01$ vs control; $n=5$, see Figure $5 \mathrm{f}$ for representative plot). In these cells, the subsequent addition of ethanol $(30 \mathrm{mM})$ further reduced neuronal firing to $0.4 \pm 0.4 \mathrm{~Hz}(P<0.05 v s$ Gly $100 \mu \mathrm{M} ; n=5$, Figure $5 \mathrm{f})$. Both effects were sensitive to strychnine $(1 \mu \mathrm{M})$, which increased the frequency of action current firing to above that of the original control $(3.6 \pm 0.3 \mathrm{~Hz}$, ie, $138 \%$ of control, $P<0.05 ; n=5$, Figure 5f). Collectively, these findings identify the DR extrasynaptic GlyR as an important molecular target for ethanol.

Taurine, an agonist of GlyRs and $\mathrm{GABA}_{\mathrm{A}}$ Rs (Albrecht and Schousboe, 2005), is present in certain 'energy drinks', eg, 'Red Bull', in substantial amounts ( $1 \mathrm{~g} / 250 \mathrm{ml} /$ can http:// www.canadian-seeker.com/ADHD/Taurine.htm). Given the popular trend to consume alcohol in combination with such 'energy drinks', it is conceivable that ethanol and taurine act in unison to enhance GlyR function. Unfortunately, commercially available taurine is contaminated by glycine (Lape et al, 2008). Therefore, we investigated the action of ethanol $(30 \mathrm{mM})$ in the presence of guanidinoethanesulfonic acid (GES), a selective taurine re-uptake inhibitor (Albrecht 


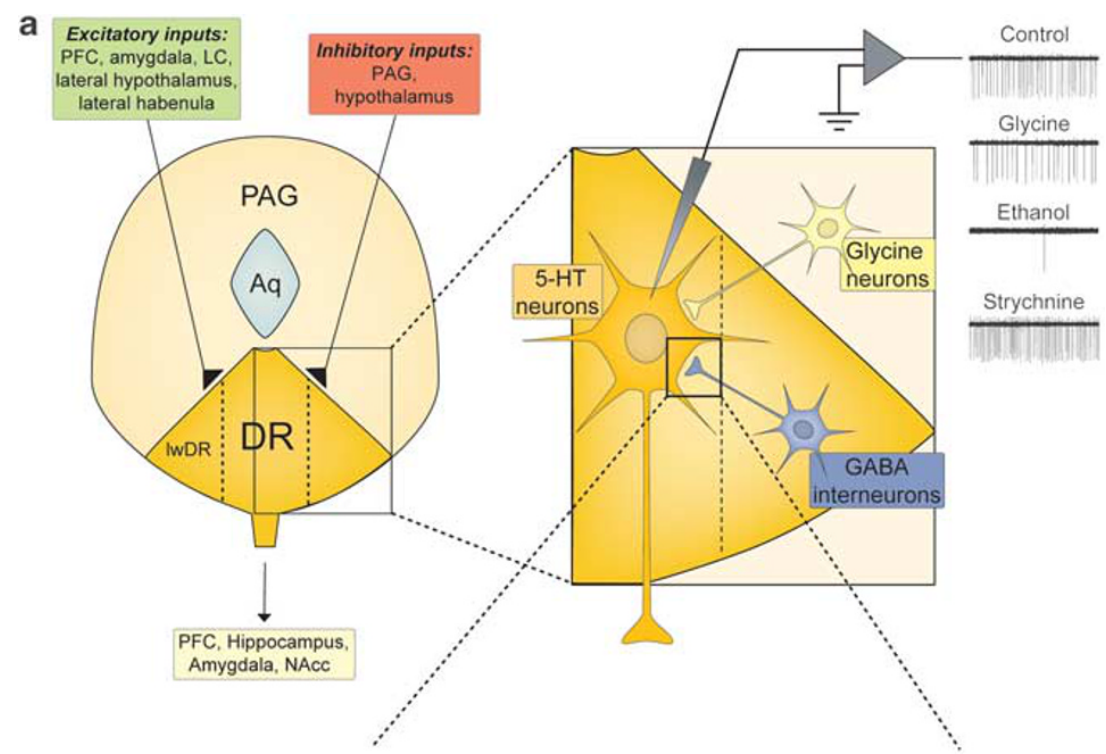

b

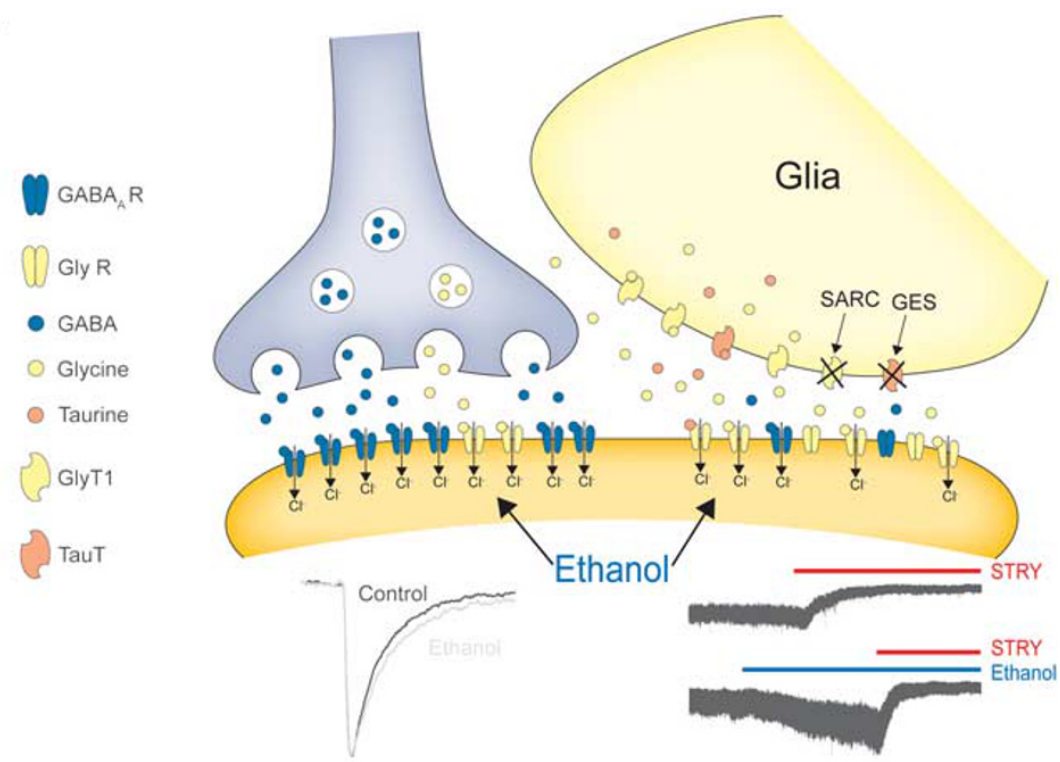

Figure 7 A model for the role of inhibitory transmission in the mouse dorsal raphe nuclei and the relevance of modulation of the glycinergic conductance to the DR neuronal output. (a) A simplified schematic representation of the topographical organization of dorsal raphe nuclei illustrating its principal neuronal inputs and outputs. Inhibitory inputs to 5-HT neurons (ochre) are mediated by both $\mathrm{GABA}_{A}$ receptors $\left(\mathrm{GABA}_{A} \mathrm{Rs}_{\mathrm{s}}\right.$ ) and strychninesensitive glycine receptors (GlyRs). GABAergic inputs (grey) are mainly, but not exclusively, of local origin, whereas the glycinergic neuronal inputs (yellow) originate out with the dorsal raphe (eg, PAG and the reticular system). In addition, glial-derived taurine/ $\beta$-alanine (salmon pink) and glycine can activate the inhibitory tonic conductance (see below). The glycinergic conductance exerts a powerful control over DR neuronal excitability (see traces right). Enhancement of the conductance by glycine or by ethanol and suppression by strychnine significantly reduces and increases, respectively, the action potential discharge of DR 5-HT neurons. (b) Our findings indicate that DR 5-HT neurons utilize a unique synergistic organization for inhibition whereby $\mathrm{GABA}_{A} \mathrm{Rs}$ (blue) primarily mediate synaptic or 'phasic' inhibition, whereas extra-synaptic GlyRs (yellow) provide a large 'tonic' conductance that profoundly decreases neuronal excitability (top trace right). A behaviorally relevant concentration $(30 \mathrm{mM})$ of ethanol selectively enhances the extrasynaptic (bottom trace right) and synaptic (left trace) glycinergic conductance to consequently suppress DR neuronal firing (see traces in panel (a)) but has little effect upon $\mathrm{GABA}_{A} \mathrm{R}$-mediated synaptic inhibition. The large GlyR-mediated conductance is additionally greatly increased by clomethiazole, which is used clinically to treat alcohol withdrawal (Williams and McBride, 1998), and by sarcosine, which inhibits the GlyTI transporter, an action recently reported to decrease ethanol intake and preference in rats (Molander et al, 2007). Moreover, taurine, an ingredient of certain energy drinks, often taken together with ethanol, enhances the effect of ethanol upon the tonic glycinergic conductance (see Discussion for additional details). PFC, prefrontal cortex; LC, locus coreleus; Aq, aqueduct; PAG, peri-aqueductal grey; DR, dorsal raphe; IwDR, DR lateral wing; NAcc, nucleus accumbens; GlyTI, glycine transporter I; TauT, taurine transporter.

and Schousboe, 2005; Alexander et al, 2011). In the presence of bicuculline $(30 \mu \mathrm{M})$, to antagonize any $\mathrm{GABA}_{\mathrm{A}} \mathrm{R}$-mediated contribution by taurine (Albrecht and Schousboe, 2005), GES $(300 \mu \mathrm{M})$, on all neurons tested, induced an inward current ( $-23 \pm 3 \mathrm{pA}, n=5)$, which was further enhanced by $30 \mathrm{mM}$ ethanol $(\Delta I=-30 \pm 13 \mathrm{pA}, n=5$, ie, an $\sim 2$-fold increase, $P<0.05$ vs GES alone- Figure $6 \mathrm{a}, \mathrm{b}$ and $\mathrm{d}$ ). Both the GES and the GES + ethanol-induced currents were blocked 
by strychnine $(0.5 \mu \mathrm{M})$. Our observation of an interaction of ethanol and taurine on the DR GlyR tonic current suggests that the popular trend to drink ethanol together with 'energy drinks' containing considerable amounts of taurine warrants caution.

We next explored whether known (clomethiazole) and putative treatments (inhibitors of glycine transporters) for alcohol abuse, in common with ethanol, influenced these extrasynaptic GlyRs. Clomethiazole enhances the function of both $\mathrm{GABA}_{\mathrm{A}}$ Rs and GlyRs (Hales and Lambert, 1992) and in Europe is a common treatment for alcohol withdrawal (Williams and McBride, 1998). In common with ethanol, the glycine $(30 \mu \mathrm{M})$-induced inward current $(-67 \pm 16 \mathrm{pA})$ was further enhanced by the subsequent application of clomethiazole $(100 \mu \mathrm{M}, \Delta I=-55 \pm 12 \mathrm{pA}$ in seven of the eight cells recorded (88\%); ie, an $\sim 2$-fold increase of the glycine $(30 \mu \mathrm{M})$-evoked conductance) and blocked by strychnine $(0.5 \mu \mathrm{M})$ in all neurons tested (Figure 6b). However, in contrast to ethanol, clomethiazole $(100 \mu \mathrm{M})$ additionally enhanced $\mathrm{GABA}_{\mathrm{A}} \mathrm{R}$-mediated synaptic transmission by increasing the amplitude and prolonging the decay of $\mathrm{GABA}_{\mathrm{A}} \mathrm{R}$-mediated mIPSCs but with no effect on their frequency (Supplementary Table S3). A selective GlyT1 inhibitor (ORG 25935) decreases ethanol intake and preference in rats (Molander et al, 2007). Here, in all neurons tested, the selective GlyT1 inhibitor, sarcosine $(300 \mu \mathrm{M}$; Alexander et al, 2011) induced an inward current $(-85 \pm 26 \mathrm{pA}, n=11)$, which was reversed by strychnine $(0.5 \mu \mathrm{M}$-Figure $6 \mathrm{c}$ and $\mathrm{d})$.

\section{GlyRs of the NAcc are Relatively Insensitive to Ethanol}

Previous reports have indicated the presence of GlyRs in the NAcc (Martin and Siggins, 2002), a finding consistent with our immunohistochemical analysis (Figure $3 \mathrm{~d}-\mathrm{f}$ ). Given the established role of this brain region in addiction and reward (Koob and Volkow, 2010), we explored whether our findings for DR neurons extended to accumbal MSNs. Under identical recording conditions to those utilized for DR neurons, strychnine $(0.5 \mu \mathrm{M})$ did not reveal any synaptic or tonic glycinergic conductance in MSNs. However, on all MSNs tested the focal application of glycine $(1 \mathrm{mM})$ consistently elicited an inward current $(-353 \pm 57 \mathrm{pA}$; $n=16)$, which was blocked by strychnine $(0.5 \mu \mathrm{M})$. Similarly, bath-applied glycine $(100 \mu \mathrm{M})$ induced an inward current ( $-41 \pm 4 \mathrm{pA}, n=4$ ) on all neurons tested, albeit of a much smaller magnitude than that produced by this concentration of agonist for DR neurons $(-273 \pm 66 \mathrm{pA}$, $n=10$; Supplementary Figure S2a). However, in contrast to DR neurons, ethanol $(30 \mathrm{mM})$, in the presence of glycine $(100 \mu \mathrm{M})$, had no significant effect on the glycinergic conductance of MSNs $(\Delta I=-11 \pm 5 \mathrm{pA} ; \Delta \mathrm{RMS}=1.2 \pm 0.7$ pA; $n=6 ; P>0.05$; Supplementary Figure S2b), revealing neuronal specificity for the ethanol-GlyR interaction.

Recombinant expression studies propose ethanol enhancement of GlyR function to be subunit dependent, ie, $\alpha 1 \gg \alpha 2 / \alpha 3$ (Mascia et al, 1996). To explore the subunit composition of GlyRs in the DR and accumbal MSNs, we utilized cyclothiazide, a relatively selective inhibitor of $\alpha 2$ GlyRs compared with $\alpha 1$-GlyRs (Zhang et al, 2008). For DR neurons, the inward current evoked by the focal application of glycine was unaffected by the bath application of $100 \mu \mathrm{M}$ cyclothiazide ( $101 \pm 2 \%$ of control, $n=5 ; P>0.05)$ but, in contrast, was reduced ( $80 \pm 3 \%$ of control; $n=5 ; P<0.01$ ) for accumbal MSNs (Supplementary Figure S2c). These findings are consistent with the reported abundant and selective expression of $\alpha 1$-GlyR in the DR compared with the NAcc (Jonsson et al, 2009; http://mouse.brain-map.org/ welcome.do;jsessionid=0CDE823DFD3D02505E0EB0DF5D4 C95C4) and provide a parsimonious explanation for the selective modulation by ethanol of the glycinergic conductance in DR but not accumbal MSN neurons.

\section{DISCUSSION}

We reveal that DR serotonergic neurons utilize an unusual synergistic organization for inhibition, whereby extrasynaptic GlyRs mediate a large 'tonic' inhibition, which profoundly decreases neuronal excitability, and acts in concert with synaptic $\mathrm{GABA}_{\mathrm{A}} \mathrm{Rs}$ that primarily mediate fast 'phasic' inhibition. Importantly, a behaviorally relevant concentration of ethanol selectively enhances the GlyR phasic and tonic conductance to suppress DR neuronal firing, with little effect upon $\mathrm{GABA}_{\mathrm{A}} \mathrm{R}$-mediated synaptic or tonic inhibition.

\section{DR Neurons Exhibit a Large Extrasynaptic Glycinergic Tonic Conductance, which Influences Neuronal Excitability}

Strychnine-sensitive GlyRs have traditionally been associated with the regulation of inhibition in lower centres of the CNS, eg, spinal cord (Yevenes and Zeilhofer, 2011). However, it is now recognized that these receptors are additionally expressed in higher centres, including the hippocampus and prefrontal cortex, where they are primarily expressed extrasynaptically (Badanich et al, 2013; Chattipakorn and McMahon, 2002; Keck and White, 2009; $\mathrm{Lu}$ and $\mathrm{Ye}, 2011 ; \mathrm{Xu}$ and Gong, 2010). For $\mathrm{GABA}_{\mathrm{A}} \mathrm{Rs}$, tonic inhibition mediated by extrasynaptic $\mathrm{GABA}_{\mathrm{A}} \mathrm{Rs}$ has emerged as a powerful mechanism to influence neuronal excitability of higher CNS centres and an important target for a variety of clinically relevant drugs (Belelli et al, 2009; Farrant and Nusser, 2005). By contrast, equivalent evidence for an analogous form of inhibition mediated by extrasynaptic GlyRs is limited. Utilizing immunohistochemistry and electrophysiology, we reveal that all serotonergic DR neurons express extrasynaptic GlyRs, and for the majority of these neurons their receptor expression is sufficient to mediate a large tonic conductance, caused by their activation by ambient endogenous agonist. The neurophysiological significance of this conductance is revealed by the antagonist strychnine, which both depolarized and increased the excitability of these serotonergic neurons, suggesting that this GlyR-mediated tonic conductance will influence 5-HT release. Modulation of anxiety-like behavior in rodents is associated with region-selective changes in serotonergic transmission in the terminal fields of the DR projections (Rueter and Jacobs, 1996; Storey et al, 2006). Whether in vivo this glycinergic conductance influences 5-HT release and consequently influences behaviors such as anxiety provides scope for future investigation. 
Ethanol Selectively Decreases DR Neuronal Excitability Via an Action at Strychnine- and Ethanol-Sensitive GlyRs

Importantly, a concentration of ethanol impairing physiological functions $(30 \mathrm{mM})$ caused a large enhancement of the GlyR-mediated tonic conductance and a consequent decrease in DR excitability. Interestingly, in vivo acute ethanol decreased the firing rate in a proportion $(67 \%)$ of rat DR serotonergic neurons similar to that affected in vitro in the present study (Pistis et al, 1997).

Potentially, ethanol could indirectly increase the glycinergic conductance by releasing taurine as a consequence of astrocyte swelling (Albrecht and Schousboe, 2005; Adermark et al, 2011). However, we suggest this scenario is unlikely for the following reasons. First, ethanol actions are selective for DR neurons GlyRs, as accumbal GlyRs appeared insensitive, despite ethanol inducing both taurine release and astrocyte swelling in this region (Adermark et al, 2011). As taurine will activate GlyRs in the NAcc, these observations strongly suggest ethanol actions to be mediated by a potentiation of GlyR function. Second, GlyR mIPSCs are significantly prolonged by ethanol. As taurine would not prolong the synaptic response, this observation suggests that ethanol directly modulates GlyRs expressed synaptically.

Among other putative ethanol candidates, $\mathrm{GABA}_{\mathrm{A}} \mathrm{Rs}$, particularly extrasynaptic receptors incorporating the $\delta$ subunit, have been proposed as clinically relevant targets (Korpi et al, 2007; Mody et al, 2007). However, our immunohistochemistry revealed no evidence for expression of $\delta$-GABA $\mathrm{As}$ in serotonergic DR neurons. Furthermore, the glycine-enhancing effect of ethanol was highly selective. Thus, in common with other reports (Badanich et al, 2013; Weitlauf and Woodward, 2008), ethanol was ineffective on the few neurons that exhibited a $\mathrm{GABA}_{\mathrm{A}} \mathrm{R}$-mediated tonic current, although for some neurons it did cause a modest increase in the frequency of $\mathrm{GABA}_{\mathrm{A}} \mathrm{R}$-mediated mIPSCs.

Is this effect of ethanol neuron selective? Consistent with previous reports for the rat (Martin and Siggins, 2002; Molander and Soderpalm, 2005), our immunohistochemistry reveals expression of GlyRs in mouse accumbens MSNs, albeit at a significantly lower level than in the DR. However, in contrast to the DR, our electrophysiological studies reveal these GlyRs are not tonically active. Furthermore, when activated by added glycine these GlyRs are ethanol insensitive. This differential action of ethanol may reflect the preferential expression of ethanol-sensitive $\alpha 1$-GlyRs in the DR compared with accumbal MSNs (Jonsson et al, 2009), where our pharmacological analysis suggests $\alpha 2$-GlyRs to be the dominant isoform. This interpretation is consistent with the reported selectivity of ethanol for $\alpha 1-v s$ 2-GlyRs (Mascia et al, 1996; Yevenes et al, 2010), and the recent report selectively implicating $\alpha 1$-GlyRs in the potentiating actions of zinc on ethanol sensitivity of GlyRs (McCracken et al, 2013). Interestingly, some of the actions of ethanol in the NAcc have been proposed to be secondary to an elevation in the DA outflow, mediated by strychnine-sensitive GlyRs located on accumbal GABAergic MSNs (Chau et al, 2010). Our findings would appear inconsistent with this interpretation, although it remains possible that ethanol elevates DA content in the NAcc via a distinct strychnine-sensitive GlyR isoform (other than $\alpha 2$ ), at locations other than those on MSN neurons, eg, on GABAergic terminals impinging on the dopaminergic cell body within the VTA or dopaminergic terminals within the NAcc. The former suggestion is supported by the proposal that glycine regulation of $\mathrm{DA}$ levels requires activation of dopaminergic cell bodies (Hernandes et al, 2007; Molander and Soderpalm, 2005). Furthermore, in support, intra-VTA injections of glycine decreases ethanol consumption and preference in rats in a strychninesensitive fashion (Li et al, 2012).

Could these extrasynaptic GlyRs be a behaviorally relevant ethanol target? Given that blockade of the tonic current by strychnine is associated with an increase in neuronal excitability, it is conceivable that ethanol enhancement of this conductance and the associated decrease of excitability may reduce 5-HT release and consequently influence behavior. Indeed, drugs that reduce ethanol intake interfere with the serotonergic system (Lanteri et al, 2008; LeMarquand et al, 1994a, b). The terminal fields of the DR serotonergic neurons include prefrontal cortex, hippocampus, amygdala, and NAcc, all areas implicated in the mediation of anxiety, reward, and alcohol action (Koob and Volkow, 2010; Kranz et al, 2010; Vengeliene et al, 2008). Furthermore, a reduction in 5-HT activity in the medial prefrontal cortex (mPFC) is associated with reduced ethanol intake (Deckel et al, 1997), and a paradigm that decreases anxiogenic-like behavior in rodents is associated with a reduction of 5-HT release in the mPFC (Storey et al, 2006). Therefore, we speculate that ethanol enhancement of DR GlyR function may influence serotonergic activity and consequently contribute to the anxiolytic properties of this alcohol. Future behavioral studies are required to explore this concept.

\section{Summary}

Collectively, we provide the first demonstration that the activity of DR serotonergic neurons is greatly influenced by a tonic conductance mediated by extrasynaptic GlyRs. Importantly, this inhibitory conductance is selectively enhanced by ethanol. A schematic representation of the proposed role of inhibitory transmission mediated by GlyRs in the mouse DR and its influence on neuronal excitability is depicted in Figure 7.

Given that the DR is implicated in stress, anxiety, and reward, these extrasynaptic GlyRs may be a clinically relevant target for ethanol (Baer et al, 2003) and may provide the impetus to develop GlyR-based therapeutics for the treatment of alcohol withdrawal. This concept is supported by the demonstration that both clomethiazole (a current treatment for alcohol withdrawal) and a GlyT1 inhibitor (active in animal models of alcohol withdrawal) greatly enhance the DR tonic conductance at clinically relevant concentrations (Harris et al, 2008).

\section{FUNDING AND DISCLOSURE}

EPM and SJG were supported by a Capacitive and a Case Award BBSRC Studentship, respectively (BBS/S/H/2005/ 12019 and BB/H530562/1 the latter in conjunction with Merck Sharp and Dohme). The work was further supported by the Medical Research Council UK (to DB and JJL G1000008), Tenovus Scotland (to DB and JJL) and an 
Anonymous Trust Grant (to DB). The authors declare no conflict of interest.

\section{REFERENCES}

Adermark L, Clarke RB, Olsson T, Hansson E, Söderpalm B, Ericson M (2011). Implications for glycine receptors and astrocytes in ethanol-induced elevation of dopamine levels in the nucleus accumbens. Addict Biol 16: 43-54.

Aguayo LG, Pancetti FC (1994). Ethanol modulation of the $\gamma$ aminobutyric $\operatorname{acid}_{\mathrm{A}^{-}}$and glycine-activated $\mathrm{Cl}^{-}$current in cultured mouse neurons. J Pharmacol Exp Ther 270: 61-69.

Albrecht J, Schousboe A (2005). Taurine interaction with neurotransmitter receptors in the CNS: an update. Neurochem Res 30: 1615-1621.

Alexander SPH, Mathie A, Peters JA (2011). Guide to Receptors and Channels, 5th Ed 164: S213-S278.

Badanich KA, Mulholland PJ, Beckley JT, Trantham-Davidson H, Woodward JJ (2013). Ethanol reduces neuronal excitability of lateral orbitofrontal cortex neurons via a glycine receptor dependent mechanism. Neuropsychopharmacology 38: 1176-1188.

Baer K, Waldvogel HJ, During MJ, Snell RG, Faull RL, Rees MI (2003). Association of gephyrin and glycine receptors in the human brainstem and spinal cord: an immunohistochemical analysis. Neuroscience 122: 773-784.

Belelli D, Harrison NL, Maguire J, Macdonald RL, Walker MC, Cope DW (2009). Extrasynaptic $\mathrm{GABA}_{\mathrm{A}}$ receptors: form, pharmacology, and function. J Neurosci 29: 12757-12763.

Briatore F, Patrizi A, Viltono L, Sassoe-Pognetto M, Wulff P (2010). Quantitative organization of GABAergic synapses in the molecular layer of the mouse cerebellar cortex. PLoS One 5: e12119.

Brown RE, McKenna JT, Winston S, Basheer R, Yanagawa Y, Thakkar MM et al (2008). Characterization of GABAergic neurons in rapid-eye-movement sleep controlling regions of the brainstem reticular formation in GAD67-green fluorescent protein knock-in mice. Eur J Neurosci 27: 352-363.

Calizo LH, Akanwa A, Ma X, Pan YZ, Lemos JC, Craige C et al (2011). Raphe serotonin neurons are not homogenous: electrophysiological, morphological and neurochemical evidence. Neuropharmacol 61: 524-543.

Chattipakorn SC, McMahon LL (2002). Pharmacological characterization of glycine-gated chloride currents recorded in rat hippocampal slices. J Neurophysiol 87: 1515-1525.

Chau P, Hoifodt-Lido H, Lof E, Soderpalm B, Ericson M (2010). Glycine receptors in the nucleus accumbens involved in the ethanol intake-reducing effect of acamprosate. Alcohol Clin Exp Res 34: 39-45.

Corteen NL, Cole TM, Sarna A, Sieghart W, Swinny JD (2011). Localization of $\mathrm{GABA}_{\mathrm{A}}$ receptor $\alpha$ subunits on neurochemically distinct cell types in the rat locus coeruleus. Eur J Neurosci 34: $250-262$.

Deckel AW, Shoemaker WJ, Arky L (1997). Effects of 5,7dihydroxytryptamine lesions of the prefrontal cortex on consumption of sucrose-ethanol solutions: relationship to prefrontal monoamines. Alcohol Clin Exp Res 21: 631-636.

Dixon CI, Morris HV, Breen G, Desrivieres S, Jugurnauth S, Steiner $\mathrm{RC}$ et al (2010). Cocaine effects on mouse incentive-learning and human addiction are linked to alpha2 subunit-containing GABAA receptors. Proc Natl Acad Sci U S A 107: 2289-2294.

Eggers ED, Berger AJ. (2004). Mechanisms for the modulation of native glycine receptor channels by ethanol. J Neurophysiol 91: 2685-2695.

Farrant M, Nusser Z (2005). Variations on an inhibitory theme: phasic and tonic activation of $\mathrm{GABA}_{\mathrm{A}}$ receptors. Nat Rev Neurosci 6: 215-229.

Gonzales RA, Job MO, Doyon WM (2004). The role of mesolimbic dopamine in the development and maintenance of ethanol reinforcement. Pharmacol Ther 103: 121-146.
Hales TG, Lambert JJ (1992). Modulation of GABA A and glycine receptors by chlormethiazole. Eur J Pharmacol 210: 239-246.

Harris RA, Trudell JR, Mihic SJ (2008). Ethanol's molecular targets. Sci Signal 1: re7.

Hernandes MS, de Magalhaes L, Troncone LR (2007). Glycine stimulates the release of labeled acetylcholine but not dopamine nor glutamate from superfused rat striatal tissue. Brain Res 1168: 32-37.

Jonsson S, Kerekes N, Hyytia P, Ericson M, Soderpalm B (2009). Glycine receptor expression in the forebrain of male AA/ANA rats. Brain Res 1305: S27-S36.

Judge SJ, Ingram CD, Gartside SE (2004). GABA receptor modulation of 5-HT neuronal firing: characterization and effect of moderate in vivo variations in glucocorticoid levels. Neurochem Int 45: 1057-1065.

Keck T, White JA (2009). Glycinergic inhibition in the hippocampus. Rev Neurosci 20: 13-22.

Koob GF, Volkow ND (2010). Neurocircuitry of addiction. Neuropsychopharmacology 35: 217-238.

Korpi ER, Debus F, Linden AM, Malécot C, Leppä E, Vekovischeva $\mathrm{O}$ et al (2007). Does ethanol act preferentially via selected brain $\mathrm{GABA}_{\mathrm{A}}$ receptor subtypes? The current evidence is ambiguous. Alcohol 41: 163-176.

Kranz GS, Kasper S, Lanzenberger R (2010). Reward and the serotonergic system. Neuroscience 166: 1023-1035.

Lanteri C, Salomon L, Torrens Y, Glowinski J, Tassin JP (2008). Drugs of abuse specifically sensitize noradrenergic and serotonergic neurons via a non-dopaminergic mechanism. Neuropsychopharmacology 33: 1724-1734.

Lape R, Colquhoun D, Sivilotti LG (2008). On the nature of partial agonism in the nicotinic receptor superfamily. Nature 454: 722-727.

LeMarquand D, Pihl RO, Benkelfat C (1994a). Serotonin and alcohol intake, abuse, and dependence: clinical evidence. Biol Psychiatry 36: 326-337.

LeMarquand D, Pihl RO, Benkelfat C (1994b). Serotonin and alcohol intake, abuse, and dependence: findings of animal studies. Biol Psychiatry 36: 395-421.

Li J, Nie H, Bian W, Dave V, Janak PH, Ye JH (2012). Microinjection of glycine into the ventral tegmental area selectively decreases ethanol consumption. J Pharmacol Exp Ther 341: 196-204.

Lorenzo LE, Russier M, Barbe A, Fritschy JM, Bras H (2007). Differential organization of $\gamma$-aminobutyric acid type $A$ and glycine receptors in the somatic and dendritic compartments of rat abducens motoneurons. J Comp Neurol 504: 112-126.

Lu Y, Ye JH (2011). Glycine-activated chloride currents of neurons freshly isolated from the prefrontal cortex of young rats. Brain Res 1393: 17-22.

Lyness WH, Smith FL (1992). Influence of dopaminergic and serotonergic neurons on intravenous ethanol self-administration in the rat. Pharmacol Biochem Behav 42: 187-192.

Martin G, Siggins GR (2002). Electrophysiological evidence for expression of glycine receptors in freshly isolated neurons from nucleus accumbens. J Pharmacol Exp Ther 302: 1135-1145.

Mascia MP, Mihic SJ, Valenzuela CF, Schofield PR, Harris RA (1996). A single amino acid determines differences in ethanol actions on strychnine-sensitive glycine receptors. Mol Pharmacol 50: 402-406.

McCracken LM, Blednov YA, Trudell JR, Benavidez JM, Betz H, Harris RA (2013). Mutation of a zinc-binding residue in the glycine receptor $\alpha 1$ subunit changes ethanol sensitivity in vitro and alcohol consumption in vivo. J Pharmacol Exp Ther 344: 489-500.

Mihalek RM, Bowers BJ, Wehner JM, Kralic JE, VanDoren MJ, Morrow AL et al (2001). $\mathrm{GABA}_{\mathrm{A}}$-receptor $\delta$ subunit knockout mice have multiple defects in behavioral responses to ethanol. Alcohol Clin Exp Res 25: 1708-1718.

Mody I, Glykys J, Wei W (2007). A new meaning for "Gin \& Tonic": tonic inhibition as the target for ethanol action in the brain. Alcohol 41: 145-153. 
Molander A, Lido HH, Lof E, Ericson M, Soderpalm B (2007). The glycine reuptake inhibitor Org 25935 decreases ethanol intake and preference in male wistar rats. Alcohol Alcohol 42: 11-18.

Molander A, Soderpalm B (2005). Glycine receptors regulate dopamine release in the rat nucleus accumbens. Alcohol Clin Exp Res 29: 17-26.

Neher E (1992). Correction for liquid junction potentials in patch clamp experiments. Methods Enzymol 207: 123-131.

Nutt DJ, King LA, Phillips LD (2010). Drug harms in the UK: a multicriteria decision analysis. Lancet 376: 1558-1565.

Perkins DI, Trudell JR, Crawford DK, Alkana RL, Davies DL (2010). Molecular targets and mechanisms for ethanol action in glycine receptors. Pharmacol Ther 127: 53-65.

Perkins KL (2006). Cell-attached voltage-clamp and current-clamp recording and stimulation techniques in brain slices. J Neurosci Methods 154: 1-18.

Pfeiffer F, Simler R, Grenningloh G, Betz H (1984). Monoclonal antibodies and peptide mapping reveal structural similarities between the subunits of the glycine receptor of rat spinal cord. Proc Natl Acad Sci USA 81: 7224-7227.

Pistis M, Muntoni AL, Gessa G, Diana M (1997). Effects of acute, chronic ethanol and withdrawal on dorsal raphe neurons: electrophysiological studies. Neuroscience 79: 171-176.

Rampon C, Peyron C, Gervasoni D, Pow DV, Luppi PH, Fort P (1999). Origins of the glycinergic inputs to the rat locus coeruleus and dorsal raphe nuclei: a study combining retrograde tracing with glycine immunohistochemistry. Eur J Neurosci 11: 1058-1066.

Rueter LE, Jacobs BL (1996). A microdialysis examination of serotonin release in the rat forebrain induced by behavioral/ environmental manipulations. Brain Res 739: 57-69.

Scimemi A, Semyanov A, Sperk G, Kullmann DM, Walker MC (2005). Multiple and plastic receptors mediate tonic $\mathrm{GABA}_{\mathrm{A}}$ receptor currents in the hippocampus. J Neurosci 25: 10016-10024.

Storey JD, Robertson DA, Beattie JE, Reid IC, Mitchell SN, Balfour DJ (2006). Behavioural and neurochemical responses evoked by repeated exposure to an elevated open platform. Behav Brain Res 166: $220-229$.
Swinny JD, O’Farrell E, Bingham BC, Piel DA, Valentino RJ, Beck SG (2010). Neonatal rearing conditions distinctly shape locus coeruleus neuronal activity, dendritic arborization, and sensitivity to corticotrophin-releasing factor. Int J Neuropsychopharmacol 13: 515-525.

Valenzuela CF, Cardoso RA, Wick MJ, Weiner JL, Dunwiddie TV, Harris RA (1998). Effects of ethanol on recombinant glycine receptors expressed in mammalian cell lines. Alcohol Clin Exp Res 22: 1132-1136.

Varoqueaux F, Jamain S, Brose N (2004). Neuroligin 2 is exclusively localized to inhibitory synapses. Eur J Cell Biol 83: 449-456.

Vengeliene V, Bilbao A, Molander A, Spanagel R (2008). Neuropharmacology of alcohol addiction. Br J Pharmacol 154: 299-315.

Weitlauf C, Woodward JJ (2008). Ethanol selectively attenuates NMDAR-mediated synaptic transmission in the prefrontal cortex. Alcohol Clin Exp Res 32: 690-698.

Williams D, McBride AJ (1998). The drug treatment of alcohol withdrawal symptoms: a systematic review. Alcohol Alcohol 33: $103-115$.

Wlodarczyk AI, Sylantyev S, Herd MB, Kersanté F, Lambert JJ, Rusakov DA et al (2013). GABA-independent GABAA receptor openings maintain tonic currents. J Neurosci 33: 3905-3914.

Xu TL, Gong N (2010). Glycine and glycine receptor signaling in hippocampal neurons: diversity, function and regulation. Prog Neurobiol 91: 349-361.

Yevenes GE, Moraga-Cid G, Avila A, Guzmán L, Figueroa M, Peoples RW et al (2010). Molecular requirements for ethanol differential allosteric modulation of glycine receptors based on selective G $\beta \gamma$ modulation. J Biol Chem 285: 30203-30213.

Yevenes GE, Zeilhofer HU (2011). Allosteric modulation of glycine receptors. Br J Pharmacol 164: 224-236.

Zhang XB, Sun GC, Liu LY, Yu F, Xu TL (2008). $\alpha 2$ subunit specificity of cyclothiazide inhibition on glycine receptors. Mol Pharmacol 73: 1195-1202.

Supplementary Information accompanies the paper on the Neuropsychopharmacology website (http://www.nature.com/npp) 